\title{
Assessment of the National Contact Points (NCPs) Capabilities to Interact with the European Commission in the Field of Science in Society
}

\author{
Silvia T. Trifonova
}

\begin{abstract}
The main objective of the paper is to assess the National Contact Points (NCPs) capabilities to interact with the European Commission in the field of Science in Society (SiS). Science in Society is a specific knowledge area in the Capacities Programme of the Seventh Framework Programme for Research and Technological Development (FP7) of the European Union. The survey method is applied in order to assess the potential and capacities of SiS NCPs. The obtained results from the paper demonstrate that not all SiS NCPs are capable to communicate with the Commission and much more detailed information from the Commission is needed for ensuring the efficient NCPs work. This recommendation is made for the next EU Framework Programme 'Horizon 2020'.
\end{abstract}

Index Terms-European commission, national contact points, science in society, seventh framework programme.

\section{INTRODUCTION}

Knowledge lies at the heart of the European Union's Lisbon Strategy to become the "most dynamic competitive knowledge-based economy in the world". The "knowledge triangle' - research, education and innovation - is a core factor in European efforts to meet the ambitious Lisbon goals. Numerous programmes, initiatives and support measures are carried out at the European Union (EU) level in support of knowledge.

The Seventh Framework Programme for Research and Technological Development (FP7) is a key tool to respond to Europe's needs in terms of jobs and competitiveness, and to maintain leadership in the global knowledge economy. FP7 lasts for seven years from 2007 until 2013.

In all EU Member States, in the countries associated with FP7 and in several other countries, National Contact Points (NCPs) have been set up to give personalized help and advice to researchers and organizations intending to participate. As an NCP for Bulgaria in the field of Science in Society (SiS) during the period 2007-2013 I am strongly involved in all FP7 activities and their implementation in Bulgarian research area. Key role of the NCPs is to support the EU policies of developing research for the global knowledge-based

Manuscript received March 31, 2013; revised May 30, 2013. This work was supported by the EUROSIS Project, financed by the Seventh Framework Programme for Research and Technological Development, Grant Agreement No. 217755 (special acknowledgment to the European Commission, Directorate-General Research and Innovation).

S. T. Trifonova is with Finance with the University of National and World Economy (UNWE), Faculty of Finance and Accounting, Department of Finance, Sofia, Bulgaria, and a National Contact Point (NCP) for Science in Society of the Seventh Framework Programme for Research and Technological Development for Bulgaria (e-mail: strifonova@unwe.bg). economy.

With this regard, the main objective of the paper is to assess the NCPs capabilities to interact with the European Commission in the field of SiS. The survey method is applied in order to assess the potential and capacities of SiS NCPs. A questionnaire is used for assessing NCPs capabilities to give feedback and to interact with the Commission. The paper is organized in the following manner: Part II is dedicated to the key aspects of FP7; Part III is devoted to the role of the NCPs in FP7; Part IV is focused on the assessment of NCPs capabilities to interact with the Commission in the field of Science in Society. The paper concludes with summarizing the results from the study.

\section{Key Aspects of the SeVenth Framework PROGRAMME OF THE EUROPEAN UNION}

The EU supports research and innovation through European Framework Programmes, coordinates and supports national and regional research and innovation programmes, contributes to the creation of the European Research Area (ERA) by developing the conditions for researchers and knowledge to circulate freely, and supports European organizations and researchers in their cooperation at international level. Since their launch in 1984, the Framework Programmes have played a lead role in multidisciplinary research and cooperative activities in Europe and beyond. FP7 continues that task, and is both larger and more comprehensive than earlier Framework Programmes [1].

The FP7 is the EU's main instrument for funding research in Europe. It has two main strategic objectives: first, to strengthen the scientific and technological base of the European industry; second, to encourage its international competitiveness, while promoting research that supports EU policies.

The FP7 has a total budget of EUR 53.2 billion. This represents a substantial increase compared with the previous Framework Programme FP6 (63\% at current prices), a reflection of the high priority of research in Europe. Participation in the FP7 is open to a wide range of organizations and individuals: universities, research centers, multinational corporations, SMEs (small to medium-sized enterprises), public administrations, even individuals, from anywhere in the world. Different participation rules apply depending on the research initiative in question.

The priorities in FP7 are contained within several specific programmes, such as follows: Cooperation, Ideas, People, 
Capacities and Nuclear research. The Capacities programme is aimed to help strengthen and optimize the knowledge capacities that Europe needs if it is to become a knowledge-based economy. This programme is stimulating Europe's full research potential and knowledge resources. It embraces six specific knowledge areas, including Research Infrastructures, Research for the benefit of SMEs, Regions of Knowledge, Research Potential, Science in Society and International Cooperation activities.

The specific knowledge area 'Science in Society' is aimed to build an effective and democratic European knowledge-based society, to stimulate the harmonious integration of scientific and technological endeavour and associated research policies into European society. The EU Member States have earmarked a total of EUR 330 million for funding this theme over the duration of FP7.

The initiative 'Science in Society' provides support to: 1) A more dynamic governance of the relationship between science and society, including: research on ethics in science and technology; the reciprocal influence of science and culture; conditions for an informed debate on ethics and science; strengthening potential, broadening horizons; 2) Strengthening the role of women in scientific research, including: supporting formal and informal science education in schools as well as through science centers and museums and other relevant means; reinforcing links between science education and science careers; 3) Science and society communication, including encouraging a European dimension at science events targeting the public; science prizes; 4) Trans-national cooperation among SiS NCPs.

'Science in society' is being implemented through the following mix of initiatives: a) Policy-related actions and research supported directly from this theme; b) Cooperation between EU Member States, identifying common goals, and reinforcing national practices, in the spirit of the open method of coordination; c) Promoting, supporting and monitoring the uptake and impact of 'Science in society' issues in other parts of the FP7. The theme also ensures overall coordination of issues related to $\mathrm{SiS}$ both across FP7 and within other relevant Community activities (e.g. relating to education and culture).

\section{Role of the NATIONAL CONTACT Points IN FP7}

Each country has a broad NCP network for each specific knowledge area of the FP7. NCPs are mainly responsible to provide advice to potential applicants and individual assistance within the country for the EU research funding. NCPs, each knowledgeable about the various aspects of FP7, are established in every EU Member State and in countries associated with FP7. Since NCPs are appointed for each of the areas of FP7, when seeking support the researchers should contact the NCP relevant to their area of interest.

The NCP network is an essential 'partner' for researchers and institutions in their effort to utilize the knowledge and experience existing in more advanced European regions, to establish the necessary conditions and contacts for their development and to contribute to the overall European research effort. The NCP service across Europe helps simplify access to FP7 calls, lower entry barriers for newcomers and raise the average quality of submitted proposals [2: p. 5]. As the NCPs are national structures, the type and level of services offered may differ from country to country. The typical work of NCPs is to raise awareness and support activities in FP7 at national level.

In particular, the following basic services of NCPs are available in all EU Member States: 1) Guidance on choosing thematic priorities and instruments; 2) Advice on administrative procedures and contractual issues; 3) Training and assistance on proposal writing; 4) Distribution of documentation (forms, guidelines, manuals, etc.); 5) Assistance in partner search. Specific information about each NCP service is available on its own website.

According to the Guiding Principles for setting up systems of NCPs [2], the list of tasks to be undertaken by NCPs consists of:

\section{A. Informing, Awareness Raising}

Circulate general and specific documentation on the EU Research and Technological Development (RTD) programmes, including on conditions for participation, and on possibilities and conditions for submission of proposals.

Organise promotional activities in liaison with the Commission services (e.g. infodays, seminars, conferences, newsletters, websites, fairs, etc.).

Raise awareness for the EU objectives of increasing the participation of women in the Framework Programme and of strengthening the link between science and ethics and between science and civil society.

Raise awareness for the EU objectives of increasing the participation of SMEs in the Framework Programme.

Raise awareness for other European programmes in the field of research and innovation such as CIP, Eureka and COST.

\section{B. Advising, Assisting and Training}

Explain the scope and the modalities of the whole spectrum of funding schemes to be used in FP7.

Advise on administrative procedures and legal issues (e.g. role and responsibilities of participants in a consortium, costs, rights and obligations of participants, respect of ethical rules and for the principles laid down in the Commission Recommendation C(2005)576 on the European Charter for Researchers and the Code of Conduct for their Recruitment).

Assist in partner search activities notably by disseminating calls for proposals (using EU tools such as CORDIS, cooperation networks, business support network services etc.).

Assist organisations, in particular new actors and SMEs, with a view to increasing their participation in FP7.

Organise training sessions on RTD programmes for intermediaries and information multipliers to ensure high quality of advice.

Organise training seminars for specific target groups (SMEs, universities, professional organizations, women in science, etc.) or on specific topics (legal aspects, modalities for participation, research areas covered by specific programmes, ethical rules, etc.).

Provide information for and advise participants, in particular smaller organisations and SMEs, on the setting up of appropriate management and legal structures in projects 
with large budgets and/or numerous participants.

Assist the EU services in assuring transparency and equal access to calls for new partners in on-going FP7 projects.

\section{Supporting and Feedback}

Give feedback to the Commission services on any problems and difficulties in implementing and participating in the Framework Programme.

Signpost to other Community business support network services those potential participants who require assistance, for example on general EU matters or matters relating to innovation and technology transfer.

Inform the Commission services about planned NCP activities and events requiring participation of Commission staff.

A common problem in the NCPs work is the lack of coordination of NCPs, at European level, which frequently leads to obstacles for both the NCPs and the research communities. On the one hand, NCPs often duplicate costs and efforts for solving common problems. On the other, researchers receive diversified services, which are reflected in the geographical distribution of the participation in FP projects, and face difficulties in establishing research collaborations beyond the frontiers of their countries.

Trans-national cooperation among NCPs has an important place in the architecture of FP7. This is based on the fact that Europe faces a series of major societal and global challenges where research can play a key role in providing solutions but which cannot be solved within national borders only. The level of funding explicitly coordinated between different countries and/or available for cross-border cooperation remains relatively modest in Europe, both in absolute terms and compared to funding allocated on a purely national basis. According to the Commission, the EU "2020 Strategy" should focus on key policy areas where collaboration between EU and Member States can deliver the best results, and on improved delivery through better use of the instruments at hand [3].

\section{ASSESSMENT OF THE NCPS CAPABILITIES TO INTERACT WITH THE EUROPEAN COMMISSION}

The Commission considers the NCP systems of all EU Member States and Associated Countries and the similar FP7 contacts in third countries as important partners for the implementation and management of FP7. This partnership based on shared responsibilities is a major element in assuring transparency and equal access. The Commission sees in the NCP network the main structure to give practical information and assistance to potential participants and contractors in FP7 [4].

For identifying and sharing best practices the SiS NCP network has carried out a survey aiming on revealing real potential and needs of improving their NCP capacities through trainings, networking, and capacity-building tools. This survey undertaken in 2010 contributed in mapping the NCP's skill gap.

The questionnaire for assessing SiS NCPs capabilities to give feedback and to interact with the Commission is divided into 4 sections comprising 23 questions: Section I - Personal information for NCPs; Section II - assessment of NCPs' interaction with the Commission on their request; Section IIIAssessment of the interaction of NCPs with the Commission on its request; Section IV - Recommendations by the NCPs for improving their interaction with the Commission.

The feedback is collected from 25 SiS NCPs from 24 partner countries, including: 1 NCP from Armenia, Austria, Belgium, Cyprus, Czech Republic, Estonia, Finland, Germany, Greece, Hungary, Ireland, Israel, Italy, Latvia, Luxembourg, Malta, Montenegro, Netherlands, Portugal, Romania, Slovenia, Spain, Sweden, Switzerland, Turkey, and 2 NCPs from Bulgaria.

According to the personal information of SiS NCPs the obtained results are the following:

1) Most NCPs have experience in SiS between 1 and 5 years (84\%), $12 \%$ - between 6 and 9 years and only $1 \mathrm{NCP}-$ between 10 and 13 years. Most NCPs (72\%) are women. Most NCPs are highly educated (52\% have MSc, MA or equivalent degree, $28 \%$ have $\mathrm{PhD}$, and $20 \%$ or $5 \mathrm{NCPs}$ have $\mathrm{BSc}$, BA or equivalent degree).

2) Most NCPs are affiliated to governmental organizations different from ministries $(48 \%)$, followed by those affiliated to private and non-profit organizations (20\%), to universities (16\%), and to ministries (12\%). No one NCP is affiliated to SMEs. Most NCPs (40\%) are full-time paid. $36 \%$ are part-time paid and $24 \%$ are non-paid.

3) Most NCPs devote to their work between 2 and 8 hours weekly $(36 \%)$ followed by those who work as NCPs between 8 and 24 hours weekly (32\%) and those who work less than 2 hours (24\%). Only 2 NCP works more than 24 hours per week.

According to the assessment of the NCPs interaction with the Commission on their request the results are such as follows:

1) Most NCPs ask information from the Commission several times per year. Such information concerns financial issues (asked by $62.5 \%$ of NCPs), newly published calls, upcoming calls and funded projects $(60 \%)$, statistics on calls and evaluations (64\%), outcome of proposal evaluation and completed projects $(56 \%)$, and particular submitted proposals $(52 \%)$. The share of NCPs who have never asked information from the Commission is high. Such information concerns: grand agreements (never asked by $52 \%$ of NCPs), project management issues (48\%), particular submitted proposals (44\%), and outcome of proposal evaluation and completed projects $(40 \%)$. Only one NCP have asked once per month the Commission for information concerning newly published calls, particular submitted calls, statistics of calls and evaluations, outcome of proposal evaluation, funded projects, completed projects and other issues. Some NCPs receive information as National Programme Committees members on certain subjects. For other issues these NCPs turn to their colleagues for information. In fact, NCPs need to ask more often for detailed and timely information from the Commission on particular issues of interest. This is a precondition for improving and multiplying the contacts between the Commission and the SiS NCPs.

2) Most NCPs receive information from the Commission in few days after their request. Such information concerns newly published calls and financial 
issues (63.2\%), upcoming calls (58.8\%), submitted proposals and outcomes of proposal evaluations $(50 \%)$, statistics of calls and evaluations (47.4\%), project management issues $(50 \%)$, funded projects $(44.4 \%)$, grant agreements $(41.2 \%)$, and completed projects $(38.9 \%)$. Fewer answers are given for receiving information in a week and in the period of 2-3 weeks. Only 1 NCP receives information on newly published calls in the same day. Two NCPs receive information from the Commission after several months or have never received information on certain issues.

3) Most NCPs assess as rather (not very) useful the information obtained by the Commission on their request. This information concerns submitted proposals (82.4\%), project management issues $(80 \%)$, completed projects $(75.0 \%)$, grants agreements $(70.6 \%)$, financial issues $(66.7 \%)$, outcomes of proposal evaluations $(66.7 \%)$, funded projects $(63.2 \%)$, upcoming calls $(55 \%)$ and newly published calls $(38.1 \%)$. As very useful most NCPs $(42.9 \%)$ describes the information about the newly published calls. Two NCPs receive rather useless information from the Commission on specific issues.

According to the assessment of the NCPs interaction with the Commission on its request the results are such as follows:

1) Most NCPs receive information from the Commission on its request several times per year. This information concerns the area 'Science in Society', including activities, areas, topics, funding schemes $(54.2 \%$ of all NCPs), changes in thematic priorities or administrative procedures $(47.8 \%)$, the general information about FP7 and roadmaps, and the Specific Programme 'Capacities' (41.7\%), outcomes of proposal evaluations (40.9\%), statistics of calls and evaluations and funded projects (39.1\%), newly published calls (37.5\%), invitations to submit expressions of interest (35\%), and upcoming calls (33.3\%). Only few NCPs have received information on some of above issues several times per week or once per week. As a conclusion it might be recommended that more timely information is necessary to be given by the Commission to the SiS NCPs in order to facilitate their work with their clients.

2) Most NCPs consider as rather (not very) useful the information obtained by the Commission on its request. This information concerns the 'Science in Society', including activities, areas, topics, funding schemas, upcoming calls and statistics of calls and evaluations (68\% of all NCPs), the FP7 and roadmaps (64\%), the Programme 'Capacities' and outcomes of proposal evaluations $(60 \%)$, invitations to submit expression of interest $(54.5 \%)$, changes in thematic priorities or administrative procedures and funded projects (54.2\%), and newly published calls (44\%). As absolutely useless the NCPs evaluate mostly the information about the invitations to submit expression of interest (4.5\% of NCPs) and the information on some other issues (50\% of NCPs).

3) Most NCPs assess as very and rather useful the dissemination methods used by the Commission. Very useful are the following dissemination methods: personal contact (68\% of all NCPs); joint meetings between NCPs, Programme Committee Members and Commission (56\%); participation in training events, workshops, seminars organized by the Commission (52\%); and participation in proposer's days organized by the Commission (48\%). As rather useful are the following methods: published documents, decisions, brochures, leaflets, CDs, etc. provided for further distribution (60\% of all NCPs); CORDIS website (56\%); CORDIS NCP forum (48\%); FP7 Enquiry Service $(40 \%)$. However, some of the dissemination methods are evaluated by the NCPs (4\%) as not useful at all such as CORDIS NCP forum, FP7 Enquiry Service and even strange - the participation in training events, workshops and seminars organized by the Commission. The personal contact with the Commission representatives is sustainably assessed as very useful from the majority of NCPs. As a result, the dissemination methods of the Commission need of substantial improvement, especially such methods as FP7 Enquiry Service, CORDIS NCP forum and CORDIS website. More initiatives and events (training events, workshops, seminars, proposer's days) should be arranged by the Commission for establishing close contacts and links between the NCPs as well as between the NCPs and the Commission.

4) The main difficulties met by the NCPs in their communication with the Commission are associated with the unclear/too broad information on particular issues $(44 \%$ of all NCPs). $20 \%$ from all NCPs have received complicated answers, followed by $16 \%$ from the NCPs which have received insufficient information on particular issues or non-relevant answers to their requests. Most NCPs (40\%) have obtained unclear/too broad information from the Commission concerning financial issues and project management issues, followed by $24 \%$ - on work packages and topics policy issues.

According to the recommendations made by the NCPs for improving their interaction with the Commission, the results are the following:

1) Most NCPs assess as high their capabilities to interact with the Commission on such issues like: request information from the Commission (52\% of all NCPs); provision of feedbacks to the Commission (56\%); participation in information and awareness activities organized by the Commission, initiation and organization of training activities and events supported by the Commission, and further distribution of documents, decisions, brochures, leaflets, CDs, etc. provided by the Commission (36\%).

2) As average many NCPs assess their competence to interact with the Commission on such issues like the communication with the Commission through CORDIS website and NCP forum ( $60 \%$ of all NCPs), maintenance of personal contacts with members of the Commission (62.5\%), participation as invited speakers in thematic conferences and seminars organized by the Commission (45.8\%), appropriately information about the planned NCP activities and events requiring participation of Commission staff (40\%), and initiation and organization of transnational cooperation activities and events supported by the Commission (43.5\%).

3) Several NCPs find themselves as excellent competent to interact with the Commission. The NCPs are mostly capable in further distribution of documents, decisions, brochures, leaflets, CDs, etc. provided by the Commission (32\%), followed by participation in information 
and awareness activities and events organized and supported by the Commission (20\%). 17.4\% of all NCPs assess themselves as excellent capable in initiating and organizing transnational cooperation activities and events supported by the Commission and $12 \%$ - in appropriately informing the Commission about planning NCP activities and events requiring participation of Commission staff. $8 \%$ of all NCPs are highly competent in requesting information from the Commission and only $4 \%$ - in providing feedbacks to the Commission.

4) However, still low are the competences of some NCPs to initiate and organize training activities and events supported by the Commission and to communicate with the Commission through CORDIS website and NCP forum (answered by 4 persons), to participate in information and awareness activities organized by the Commission (answered by 3 persons), to participate as invited speakers in thematic conferences and seminars organized by the Commission, to request information from the Commission, to initiate and organize transnational cooperation activities and events supported by the Commission, to maintain personal contacts with its members and to distribute documents, brochures, leaflets, CDs, etc. provided by the Commission (answered by 1 person).

5) Some NCPs are not at all capable to communicate with the Commission through CORDIS website or NCP forum or to initiate and organize transnational co-operation activities and events supported by the Commission (answered by 2 persons). $29.2 \%$ of all NCPs are not at all capable to participate as invited speakers in thematic conferences and seminars organized by the Commission.

6) Most NCPs need of further help from the Commission. This help is mainly in the form of: (a) more effective NCP training events organized on regular basis by the Commission (76\% of all NCPs); (b) more frequent meetings, seminars, workshops organized on regular basis by the Commission (68\%); (c) more frequent NCPs meetings with speakers from the Commission (56\%). In fact, there is a big fluctuation of labor in the SiS NCP network. As a result most NCPs are still needed of further training and education in the field of SiS.

The main recommendation made from the most SiS NCPs is that much more detailed information from the Commission is needed for ensuring the efficient NCPs work. This information should be in the following two areas: (a) particular calls, their outcomes and projects implementation (answered by $56 \%$ of all NCPs); (b) legal and financial issues - funding schemes, eligibility criteria (52\%). More precise information from the Commission is also necessary about the future of the FP7 and the work programme planning. As concerns the issues associated with the IPR/consortium agreements, work packages, topics policy issues, proposal writing or any other topics, according to the most NCPs there is no need of further information from the Commission in these areas.

\section{CONCLUSION}

The future orientation of the SIS Programme is to ensure that SIS is integrated into the ERA as a whole [5]. The 2020 vision for the ERA underlines that the ERA is firmly rooted in society and responsive to its needs and ambitions in pursuit of sustainable development [6].

According to the survey undertaken amongst the SiS NCPs it should be concluded that the NCPs have a close interaction with the Commission taking form in initiating and organizing transnational cooperation activities and events supported by the Commission, distributing of documents, leaflets, etc. provided by the Commission, and participating in information and awareness activities and events organized and supported by the Commission. However, the competences of some SiS NCPs to initiate and organize training activities and events supported by the Commission and to communicate with the Commission through CORDIS website and NCP forum should be improved.

\section{ACKNOWLEDGMENT}

The author thanks to Prof. Federico Foders, Kiel Institute for the World Economy, Germany, and Prof. Nikolay Nenovsky, University of National and World Economy, Bulgaria, and University of Picardie Jules Verne, France.

\section{REFERENCES}

[1] European Communities, European research in action. The Seventh Framework Programme (FP7), European Commission Research Directorate-General, 2007.

[2] European Commission, Guiding Principles for setting up systems of National Contact Points (NCP systems) for the Seventh Framework Programme for Research and Technological Development (FP7), European Commission DG RTD, 12. 12. 2007.

[3] Commission of the European Communities, Commission Working Document Consultation on the Future "EU 2020" Strategy, $\operatorname{COM}(2009), 647$, Brussels, 24. 11. 2009.

[4] O. Atak, Best Practice Book of Science in Society National Contact Points for FP7, TÜBÝTAK, EU Framework Programmes National Coordination Office, EUROSIS, October 2009.

[5] European Commission, Challenging Futures in Science in Society Emerging Trends and cutting-edge issues. The MASIS Report, Research Policy, European Commission, Directorate-General for Research, Brussels, 2009.

[6] European Commission, High Level Panel of the Socio-Economic Benefits of the European Research Area: Final Report, European Commission, Directorate-General for Research, Brussels, June 2012.

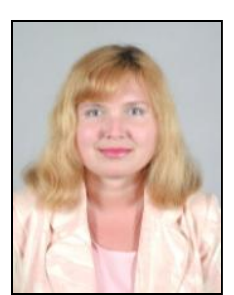

S. T. Trifonova was born in Rousse, Bulgaria on 30 April 1973. She is a Bulgarian economist, working in the fields of monetary theory and policy, international finance and banking. She graduated from the University of National and World Economy (UNWE), Department of Finance, Sofia, Bulgaria (B.A. in 1995) and Ecole Polytechnique, Department of Economics, France (M.A. in 1996). She received her Ph.D. in Finance from the UNWE, Sofia (2001). On completing her PhD she lectured at the Department of Finance, UNWE.

She works as an associate professor in Finance in Department of Finance at the UNWE, Sofia. She is affiliated with the international academic and teaching community since 1996 . Over the years she has held a number of visiting positions at several institutions including: Bank "Caisse des Depots et Consignations" (1996), University of Athens (1998), Cambridge University (2000), Kiel Institute for the World Economy (2006), etc. In 2003 she joined the Bulgarian National Bank Banking Policy Directorate, where she engaged over the years in the Payment Systems Oversight. Her major publications include: "The Role of Monetary Policy and Lessons From the Financial Crisis", Journal of US-China Public Administration, Vol. 9, No. 9, David Publishing, 2012; “A Fuzzy Logic Model for Estimation of Banking System Stability in Bulgaria" (in co-authorship with P. Zlateva), Conference Proceedings, 2012 International Conference on Innovation, Trade and Economics - ICITE, Hong Kong, 2012; "Europe 2020 strategy and its 
implications for the monetary and fiscal policies", Global Business \& Economics Anthology, Vol. II, Selected Papers, Business \& Economics Society, 2011. Her current and previous research interests include monetary theory and policy, international finance, banking, European integration, financial crises.

Assoc. Prof. Trifonova, Ph.D. is a National Contact Point for Bulgaria of the Seventh Framework Programme for Research and Technological Development (FP7) of the European Union. Her specific programme is 'Capacities' and her research area is 'Science in Society'. Assoc. Prof.
Trifonova is a member of Editorial Board of Journal of Financial Reporting and Accounting" (JFRA), Emerald Group Publishing. She is a member of Bulgarian Macroeconomic Association, Bulgarian European Community Studies Association and Bulgarian Association of University Women. She is a leader and member of many international and national research and business projects. She is a member of the EU funded projects - Eurosis, Eurosis 2.0 and SiS.Net of the European Network of FP7 Science in Society NCPs. 